\title{
Enhancement of Field Emission Properties of Carbon Nanotubes by ECR-Plasma Treatment
}

\author{
Javid Ali, ${ }^{1}$ Avshish Kumar, ${ }^{1}$ Samina Husain, ${ }^{2}$ Shama Parveen, ${ }^{1}$ Renu Choithrani, ${ }^{3}$ \\ Mohammad Zulfequar, ${ }^{1}$ Harsh, ${ }^{2}$ and Mushahid Husain ${ }^{1,2,4}$ \\ ${ }^{1}$ Department of Physics, Jamia Millia Islamia, New Delhi, India \\ ${ }^{2}$ Centre for Nanoscience and Nanotechnology, Jamia Millia Islamia, New Delhi, India \\ ${ }^{3}$ Department of Physics, Barkatullah University, Bhopal 462 026, India \\ ${ }^{4}$ M.J.P. Rohilkhand University, Bareilly, Uttar Pradesh, India
}

Correspondence should be addressed to Mushahid Husain; mush_reslab@rediffmail.com

Received 25 June 2014; Revised 28 September 2014; Accepted 7 October 2014; Published 27 October 2014

Academic Editor: Ana Benito

Copyright (C) 2014 Javid Ali et al. This is an open access article distributed under the Creative Commons Attribution License, which permits unrestricted use, distribution, and reproduction in any medium, provided the original work is properly cited.

\begin{abstract}
We report a significant improvement in electron field emission property of carbon nanotubes film by using an electron cyclotron resonance plasma treatment. Our research results reveal that plasma treatment can modify the surface morphology and enhance the field emission characteristics of carbon nanotubes. Raman spectra indicate that plasma treated CNTs sample has lesser defects. Before plasma treatment, low current density of $6.5 \mathrm{~mA} / \mathrm{cm}^{2}$ at $3.0 \mathrm{~V} / \mu \mathrm{m}$ and at a high turn-on field $\left(E_{\text {to }}\right)$ of $2.4 \mathrm{~V} / \mu \mathrm{m}$ was observed. ECR plasma treated CNTs showed a high current density of $20.0 \mathrm{~mA} / \mathrm{cm}^{2}$ at $3.0 \mathrm{~V} / \mu \mathrm{m}$ and at a low $E_{\text {to }}$ of $1.6 \mathrm{~V} / \mu \mathrm{m}$. The calculated enhancement factors are 694 and 8721 for ECR-plasma untreated and treated carbon nanotubes, respectively. We found an increase in the enhancement factor and emission current after the ECR-plasma treatment. This may be attributed to creation of geometrical features through the removal of amorphous carbon and catalyst particles.
\end{abstract}

\section{Introduction}

Carbon nanotubes (CNTs) have great attention because of their unique morphologies, which make their uses in wide variety of applications. The different techniques for the synthesis of CNTs have been developed, such as arc discharge method, laser ablation method, and chemical vapor deposition (CVD) [1-4]. The most widely used method is CVD technique, in which the synthesis is achieved by putting a carbon source in the gas phase. One of the most promising applications of CNTs is in field emission (FE) devices [5-14]. High aspect ratio and atomically sharp radius of apex curvature of the CNTs enhance the local field and lower the threshold field for electron emission. The emission properties of CNTs are governed by the work function, crystalline structure, geometry of their tips, and so forth. In addition, the surrounding gases and impurities on the surface have also been known to strongly affect their FE characteristics. However, the effect of crystallinity of CNTs on the FE has not been much investigated till now. Schwoebel and Spindt [15] experimentally found that low-pressure hydrogen glow discharge can clean the surface contaminants in both microfabricated single molybdenum tips and arrays which resulted in a decrease of $\sim 1 \mathrm{eV}$ in the work function. Yu et al. [16] achieved a low-field electron emission in undoped nanostructure diamond by employing a hydrogen plasma heat treatment. Hydrogen plasma has been known to greatly enhance the field emission property of CNTs [17]. These references indicate that plasma treatment is an effective method to improve the field emission property of CNTs. In this paper, we report the enhancement of the field emission of CNTs by ECR-plasma treatment.

\section{Experimental}

2.1. Synthesis of Carbon Nanotubes. CNTs were successfully grown on n-type (100) Si substrate by the LPCVD method 


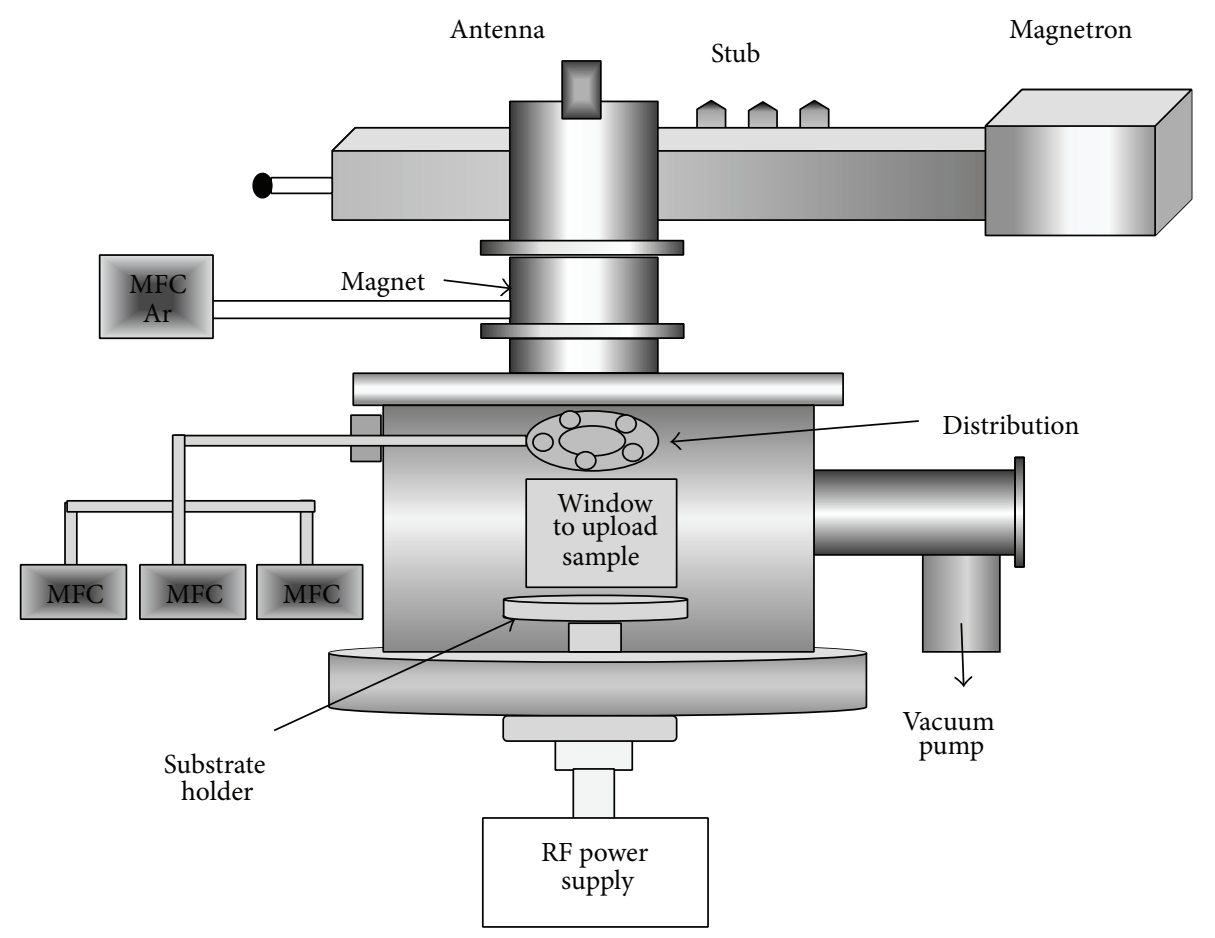

FIGURE 1: Block diagram of ECR-plasma etching system.

with Acetylene $\left(\mathrm{C}_{2} \mathrm{H}_{2}\right) /$ Ammonia $\left(\mathrm{NH}_{3}\right) /$ Hydrogen $\left(\mathrm{H}_{2}\right)$ gas mixtures at a growth temperature of $600^{\circ} \mathrm{C}$. The Si substrate was precleaned with acetone in an ultrasonic bath prior to the catalyst deposition. The Fe catalyst layer was then deposited on Si substrate by RF sputtering technique at a pressure of $10^{-3}$ torr. After depositing the catalyst layer, the substrate coated with iron was transferred to the growth chamber of the LPCVD system. The substrate was heated to $600^{\circ} \mathrm{C}$ and was held at this temperature for 20 minutes to sinter the catalyst layer by pretreating it with mixture of $\mathrm{NH}_{3}$ and $\mathrm{H}_{2}$ gas mixture at a pressure of 20 torr with flow rates 100 and $100 \mathrm{sccm}$, respectively. After this step, acetylene $\left(\mathrm{C}_{2} \mathrm{H}_{2}\right)$ $(15 \mathrm{sccm})$ was allowed to flow immediately into the chamber for 10 minutes. The total deposition process was done for 30 minutes.

2.2. ECR-Plasma System. CNTs sample was treated with $\mathrm{Ar} /$ $\mathrm{CCl}_{2} \mathrm{~F}_{2}$ plasma using ECR-plasma system. Ar gas was used to generate plasma and $\mathrm{CCl}_{2} \mathrm{~F}_{2}$ gas was used as the etchant. ECR etching process has low contamination because no electrodes are needed. Moreover, this technique has the advantage of producing low ion energies in comparison to other dry etching techniques. CNTs sample was loaded in chamber and the chamber is evacuated to a pressure of $10^{-6}$ torr. This chamber is made up of stainless steel and has the form of cylinder with a diameter of $160 \mathrm{~mm}$ and a height of about $120 \mathrm{~mm}$. ECR-plasma system is shown in Figure 1.

ECR-plasma source is RR $160 \mathrm{PQ}$ and plasma is produced due to the ionisation and excitation of neutral particles. The microwave is generated by a magnetron through a power supply. A substrate holder is facilitated with rf biasing arrangement by the application of $13.56 \mathrm{MHz}$ rf power from a power generator. Plasma is generated inside plasma chamber when the electric field lines of microwaves (axial component) and magnetic field line of the static magnetic field (radial component) stand perpendicular to each other and gyration frequency of electrons in the magnetic field is equal to the microwave frequency [18]. When the base pressure $10^{-6}$ is obtained, gas mixtures of $\mathrm{CCl}_{2} \mathrm{~F}_{2}$ and Ar were introduced into the ECR chamber at gas flow rates $6 \mathrm{sccm}$ and $8 \mathrm{sccm}$, respectively, with $50 \mathrm{~W}$ microwave powers for 5 minutes. The surface morphology of the treated CNTs was characterized by scanning electron microscope (SEM). Silicon with grown CNTs is pasted on a copper cathode with silver paste and dried at $50^{\circ} \mathrm{C}$ for field emission measurement. Field emission properties of CNTs were studied in the diode configuration. The measurements were performed at room temperature $(300 \mathrm{~K})$ in vacuum of $10^{-6}$ torr.

\section{Result and Discussion}

ECR-plasma etching is a complex process, which strongly depends on the type of ions, the time duration, and plasma power. Therefore, all these parameters will influence the field emission properties and surface morphology.

3.1. Scanning Electron Microscope. Figure 2 represents the SEM images of the CNTs that have been prepared by LPCVD system at a temperature of $600^{\circ} \mathrm{C}$ and subjected to ECRplasma treatment. The thickness of the catalyst film on silicon substrate is in the range of $10-20 \mathrm{~nm}$. The CNTs obtained by this technique also have high aspect ratio with diameter 


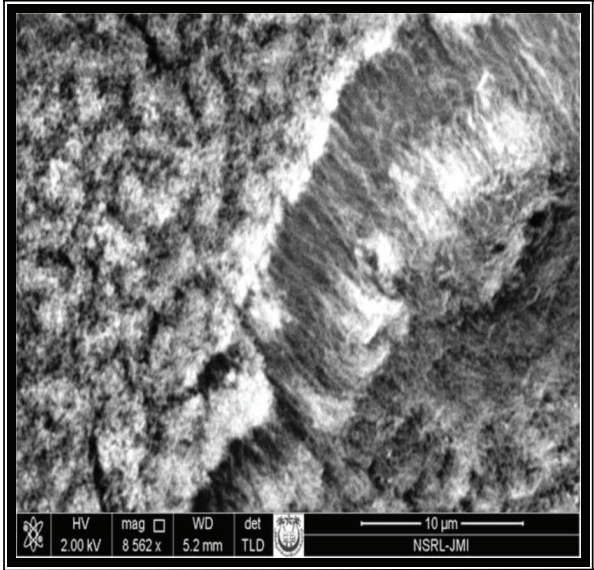

(a)

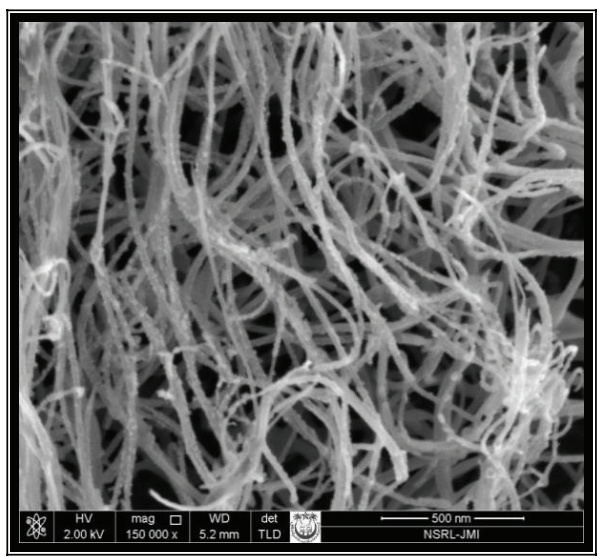

(c)

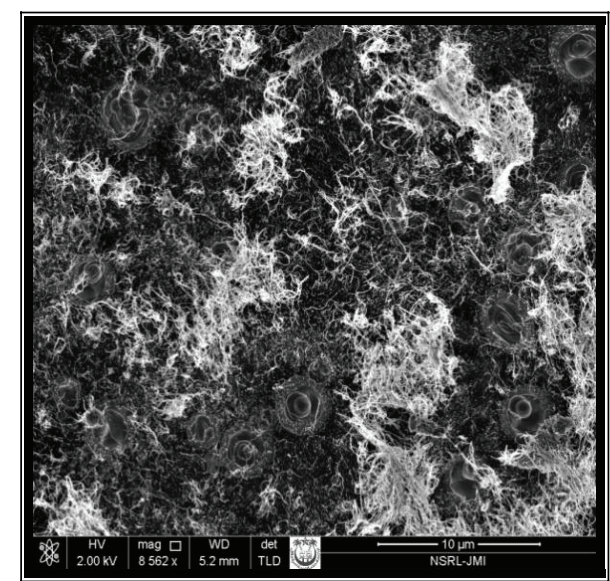

(b)

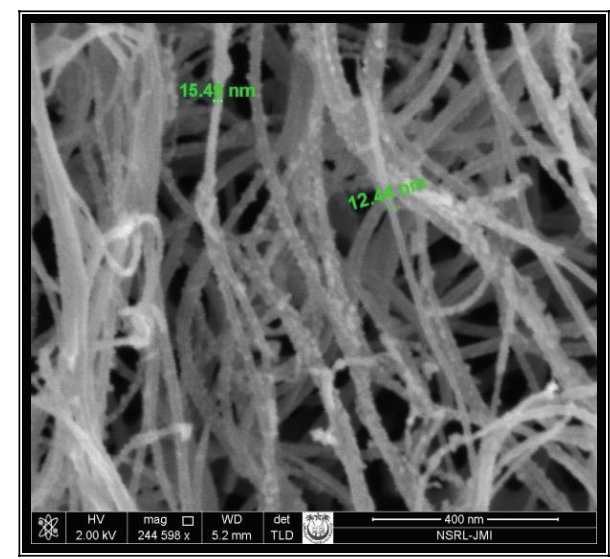

(d)

FIGURE 2: SEM images of CNTs samples (a) before and (b, c, and d) after ECR plasma.

varying from 10 to $20 \mathrm{~nm}$ and length of several micrometers. The SEM images show a clear image of the as-grown CNTs free of amorphous carbon and impurities of metal catalyst. These images also show that the density of nanotubes decreases and the spacing of plasma treated CNTs have as compared with that of the CNTs before plasma treatment. This indicates that ECR-plasma treatment may be an effective method/technique to obtain pure CNTs.

3.2. Raman Analysis. To confirm the graphitic structure of CNTs, we have also performed Raman spectroscopic measurements. In Raman spectra, there are two bands: G band and $D$ band. $G$ band is a characteristic feature of the graphitic layers and corresponds to the tangential vibration of the carbon atoms but $\mathrm{D}$ band is a typical sign for defective graphitic structures. The ratio between the G band and D band is a good indicator of the quality of bulk samples. Raman spectra of CNTs samples, before and after ECR-plasma treatment, are shown in Figure 3. Raman spectra showed two intensive peaks around $1362 \mathrm{~cm}^{-1}$ and $1586 \mathrm{~cm}^{-1}$ in both samples. The intensity ratios $I_{\mathrm{G}} / I_{\mathrm{D}}$ for the samples before and after ECR-plasma treatment are 1.06 and 1.12, respectively, which indicate that sample after plasma treatment has lesser defects.

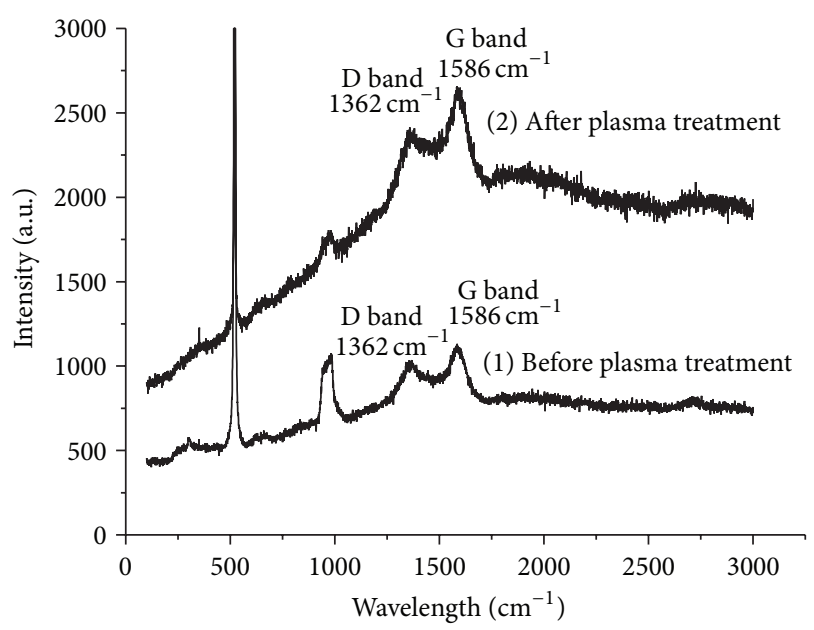

Figure 3: Raman spectra for the samples before and after ECRplasma treatment.

The peak at $520 \mathrm{~cm}^{-1}$ is due to $\mathrm{Si}$ substrate and the other peak on $1000 \mathrm{~cm}^{-1}$ can be identified as overtones of first peak [19]. 
3.3. Field Emission Measurements. Field emission (FE) is the tunnelling phenomenon which is described by quantum mechanics. In the presence of high electric field, electrons can be extracted from the sample surface. The Fowler-Nordheim (FN) theory is the most commonly used model for the emission of electrons from a metal under a strong electric field. According to FN theory, emission current density $(J)$ from the surface of emitting material is expressed as a function of the electric field $(E)$ and work function $(\phi)$ of the emitting material that is known as FN equation and written as

$$
J=A E^{2} \exp \left(-\frac{B \phi^{3 / 2}}{E}\right),
$$

where $A=1.56 \times 10^{-6} \mathrm{~A} \mathrm{eVV}^{-2}$ and $B=6.83 \times 10^{7} \mathrm{eV}^{3 / 2} \mathrm{~V}$ $\mathrm{cm}^{-1}$ are constants and $\phi$ is the work function of electron emitting material (CNT) and the applied electric field $(E)$ is defined as $\beta V / d$, where $V$ is the voltage between anode and CNT emitters as cathode, $d$ is the distance between them, and $\beta$ is the field enhancement factor. Applied electric field is enhanced more than thousand times at the tip of CNTs that can be calculated by $\beta$. Current density versus applied electric field curve $(J E)$ and $\ln \left(I / V^{2}\right)$ versus $1 / V(\mathrm{FN})$ plot are used to analyse the FE data. JE curve gives the information of turn-on field and maximum current density. Straight line of FN plot confirms that FE mechanism is taking place in our sample while slope of FN plot is used to calculate the value of $\beta$ by using simplified form of FN equation

$$
\beta=\frac{B \phi^{3 / 2} d}{m}
$$

where $m$ is the slope of FN plot $d$ distance between cathode and anode. FE measurements of as grown CNTs before and after ECR-plasma treatment were performed in a diode mode by applying negative voltage to the CNTs samples with respect stainless steel anode plate. CNTs film as electron emitter source is pasted on this copper plate with silver epoxy. The results of emission characteristics at $10^{-6}$ torr were performed to minimize the electron scattering which enhanced the electron collection at the anode plate. Cathode and anode distance is kept at $500 \mu \mathrm{m}$ (constant) during the complete FE measurements and the sample area of CNT array is $0.24 \mathrm{~cm}^{2}$.

Figure 4 displays $J E$ curves of the ECR-plasma untreated/treated CNT emitters to determine the effect of ECR plasma on FE behaviour of CNTs. As seen from this plot, the sample after ECR-plasma treatment shows about $\sim 3$ times higher current density than untreated CNTs sample. A low current density of $6.5 \mathrm{~mA} / \mathrm{cm}^{2}$ at $3.0 \mathrm{~V} / \mu \mathrm{m}$ and at a high turnon field $\left(E_{\mathrm{to}}\right)$ of $2.4 \mathrm{~V} / \mu \mathrm{m}$ was observed from untreated CNTs emitters.

In contrast, after ECR plasma treated CNTs emitter showed a high current density of $20.0 \mathrm{~mA} / \mathrm{cm}^{2}$ at $3.0 \mathrm{~V} / \mu \mathrm{m}$ and at a low $E_{\text {to }}$ of $1.6 \mathrm{~V} / \mu \mathrm{m}$. Thus, these comparison plots reveal that both the emission current and emission voltage changed favourably for their use as display devices. Figure 5 has the confirmation of FE mechanism with FN plot. Comparison of FN plot for both the CNTs samples are shown in

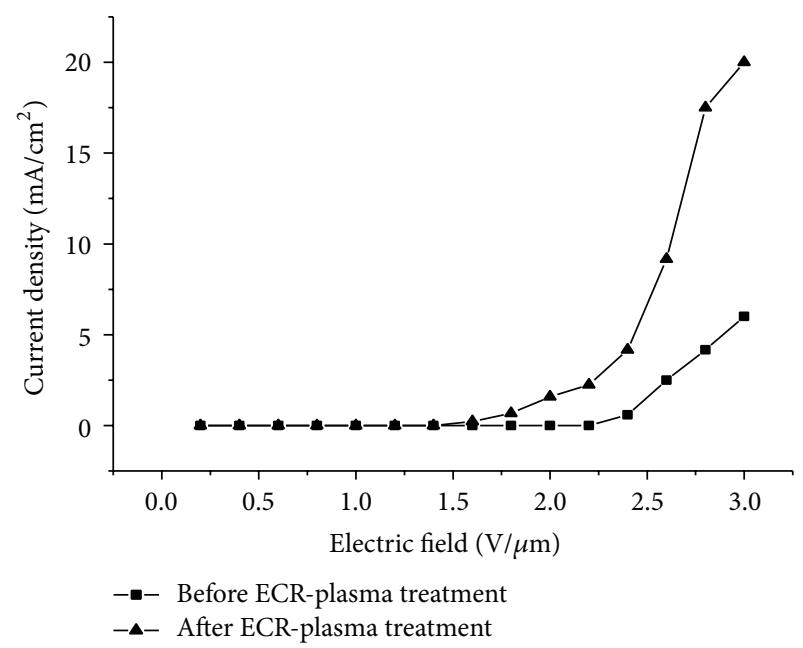

Figure 4: $J$-E curve for the samples before and after ECR-plasma treatment.

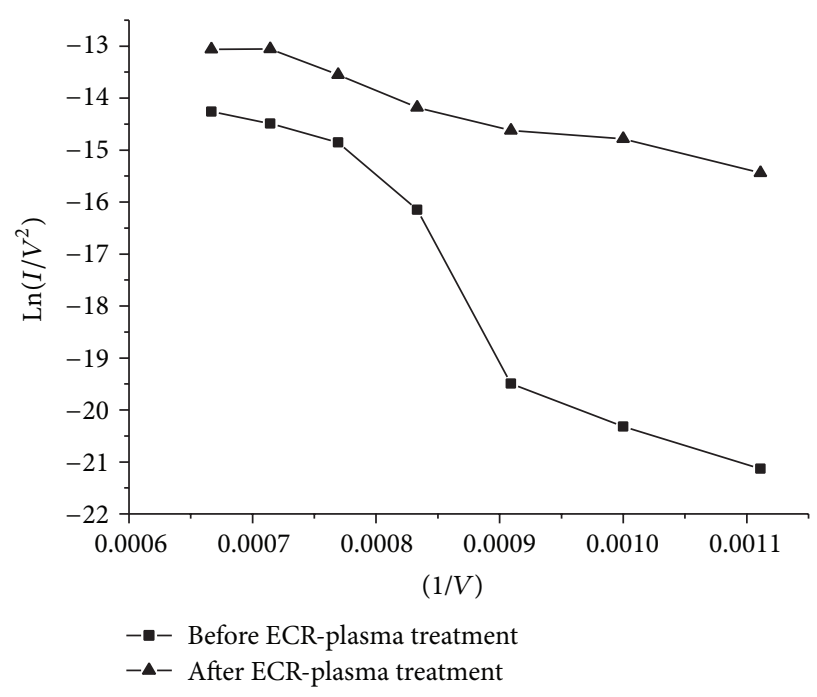

FIGURE 5: F-N plot for the samples before and after ECR-plasma treatment.

TABLE 1: Field emission parameters measured before and after ECRplasma treatment.

\begin{tabular}{lccc}
\hline Sample & $\begin{array}{c}\text { Turn-on field } \\
\left(E_{\mathrm{to}}\right)\end{array}$ & Current density & Beta $(\beta)$ \\
\hline $\begin{array}{l}\text { Before ECR-plasma } \\
\text { CNTs }\end{array}$ & $2.4 \mathrm{~V} / \mu \mathrm{m}$ & $6.5 \mathrm{~mA} / \mathrm{cm}^{2}$ & $6.94 \times 10^{2}$ \\
\hline $\begin{array}{l}\text { After ECR-plasma } \\
\text { CNTs }\end{array}$ & $1.6 \mathrm{~V} / \mu \mathrm{m}$ & $20 \mathrm{~mA} / \mathrm{cm}^{2}$ & $8.721 \times 10^{3}$ \\
\hline
\end{tabular}

Figure 5. The value of $\beta$ is calculated from slope of FN plots which comes out 694 and 8721 for ECR-plasma untreated and treated CNTs, respectively, by assuming work function $(\Phi)$ to be $5 \mathrm{eV}$ as for carbon. These FE parameters are summarised in Table 1. 


\section{Conclusion}

Carbon nanotubes have been grown successfully by LPCVD technique at a temperature of $600^{\circ} \mathrm{C}$. The SEM images show a uniform growth of MWCNTs with diameters ranging between 10 and $20 \mathrm{~nm}$ and length of up to a few microns. Raman spectra indicate that CNTs sample after plasma treatment has lesser defects. A low current density of $6.5 \mathrm{~mA} / \mathrm{cm}^{2}$ at $3.0 \mathrm{~V} / \mu \mathrm{m}$ and at a high turn-on field $\left(E_{\mathrm{to}}\right)$ of $2.4 \mathrm{~V} / \mu \mathrm{m}$ was observed from untreated CNTs. After ECR plasma treated CNTs emitter showed a high current density of $20.0 \mathrm{~mA} / \mathrm{cm}^{2}$ at $3.0 \mathrm{~V} / \mu \mathrm{m}$ and a low $E_{\text {to }}$ of $1.6 \mathrm{~V} / \mu \mathrm{m}$. The value of $\beta$ is calculated from slope of FN plots which comes out 694 and 8721 for ECR-plasma untreated and treated CNTs, respectively. These results indicate that the ECR-plasma treatment is an effective method to improve the field emission property of CNTs and CNTs can be used in display devices.

\section{Conflict of Interests}

The authors declare that there is no conflict of interests regarding the publication of this paper.

\section{Acknowledgment}

Thanks are due to Department of Electronic and Information Technology (DeitY), Ministry of Communications \& Information Technology, Government of India, for providing financial assistance in form of research project.

\section{References}

[1] Z. F. Ren, Z. P. Huang, J. W. Xu et al., "Synthesis of large arrays of well-aligned carbon nanotubes on glass," Science, vol. 282, no. 5391, pp. 1105-1107, 1998.

[2] C. J. Lee, D. W. Kim, T. J. Lee et al., "Synthesis of aligned carbon nanotubes using thermal chemical vapor deposition," Chemical Physics Letters, vol. 312, no. 5-6, pp. 461-468, 1999.

[3] W. Z. Li, S. S. Xie, L. X. Qian et al., "Large-scale synthesis of aligned carbon nanotubes," Science, vol. 274, no. 5293, pp. 17011703, 1996.

[4] S. Fan, M. G. Chapline, N. R. Franklin, T. W. Tombler, A. M. Cassell, and H. Dai, "Self-oriented regular arrays of carbon nanotubes and their field emission properties," Science, vol. 283, no. 5401, pp. 512-514, 1999.

[5] G. P. Collins and A. Zettl, "A simple and robust electron beam source from carbon nanotubes," Applied Physics Letters, vol. 9, no. 13, pp. 1969-1971, 1996.

[6] E. Milnoux, O. Groening, K. B. K. Teo et al., "Achieving highcurrent carbon nanotube emitters," Nano Letters, vol. 5, pp. 2135-2138, 2005.

[7] X. Zhao, M. Ohkohchi, M. Wang, S. Iijima, T. Ichihashi, and Y. Ando, "Preparation of high-grade carbon nanotubes by hydrogen arc discharge," Carbon, vol. 35, no. 6, pp. 775-781, 1997.

[8] X. Xu and R. G. Brandes, "A method for fabricating large-area, patterned, carbon nanotube field emitters," Applied Physics Letters, vol. 74, no. 17, pp. 2549-2551, 1999.

[9] D. W. Kang and J. S. Suh, "Fabrication temperature effect of the field emission from closed and open tip carbon nanotube arrays fabricated on anodic aluminum oxide films," Journal of Applied Physics, vol. 96, no. 9, pp. 5234-5238, 2004.

[10] S. J. Oh, J. Zhang, Y. Cheng, H. Shimoda, and O. Zhou, "Liquidphase fabrication of patterned carbon nanotube field emission cathodes," Applied Physics Letters, vol. 84, no. 19, pp. 3738-3740, 2004.

[11] K. A. Dean and B. R. Chalamala, "The environmental stability of field emission from single-walled carbon nanotubes," Applied Physics Letters, vol. 75, no. 19, pp. 3017-3019, 1999.

[12] J. M. Kim, W. B. Choi, N. S. Lee, and J. E. Jang, "Field emission from carbon nanotubes for displays," Diamond and Related Materials, vol. 9, no. 3-6, pp. 1184-1189, 2000.

[13] I. T. Han, H. J. Kim, Y. J. Par et al., "Fabrication and characterization of gated field emitter arrays with self-aligned carbon nanotubes grown by chemical vapor deposition," Applied Physics Letters, vol. 81, no. 11, pp. 2070-2072, 2002.

[14] J. Ali, A. Kumar, S. Husain, and M. Husain, "Effect of catalystdeposition methods on the alignment of carbon nanotubes grown by low pressure chemical vapor deposition," Nanoscience and Nanotechnology Letters, vol. 3, no. 2, pp. 175-178, 2011.

[15] P. R. Schwoebel and C. A. Spindt, "Field-emitter array performance enhancement using hydrogen glow discharges," Applied Physics Letters, vol. 63, no. 1, pp. 33-35, 1993.

[16] K. Yu, Z. Zhu, M. Xu, Q. Li, and W. Lu, "Electron field emission from soluble carbon nanotube films treated by hydrogen plasma," Chemical Physics Letters, vol. 373, no. 1-2, pp. 109-114, 2003.

[17] Y. M. Wong, W. P. Kang, J. L. Davidson, B. K. Choi, and J. H. Huang, "Growth and profile modification of carbon nanotubes designed for field emission applications by hydrogen plasma pretreatment," Diamond and Related Materials, vol. 15, no. 4-8, pp. 1132-1137, 2006.

[18] J. Asmussen, "Electron cyclotron resonance microwave discharges for etching and thin-film deposition," Journal of Vacuum Science \& Technology A, vol. 7, no. 3, p. 883, 1989.

[19] C. Journet, W. K. Maser, P. Bernier et al., "Large-scale production of single-walled carbon nanotubes by the electric-arc technique," Nature, vol. 388, no. 6644, pp. 756-758, 1997. 

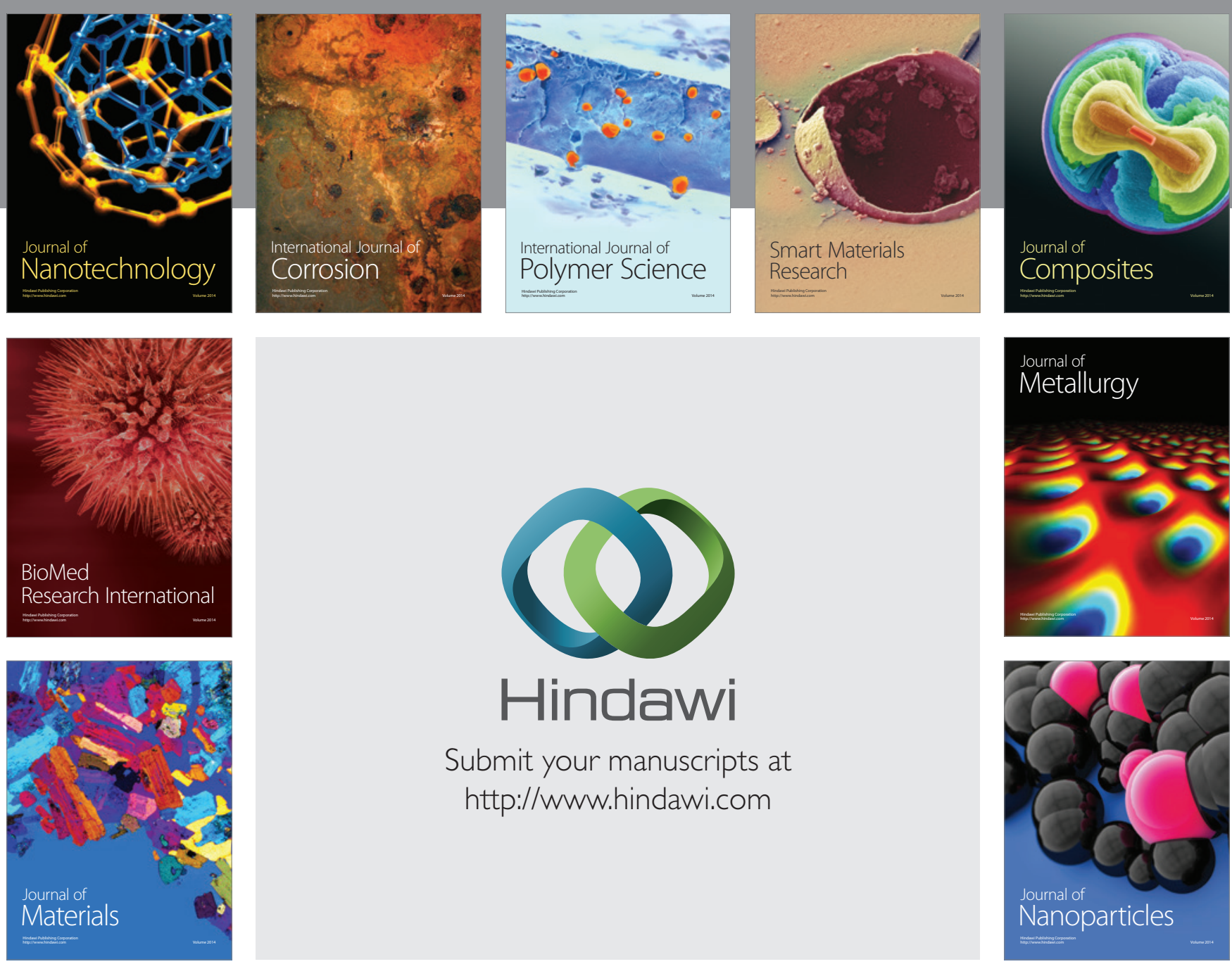

Submit your manuscripts at http://www.hindawi.com
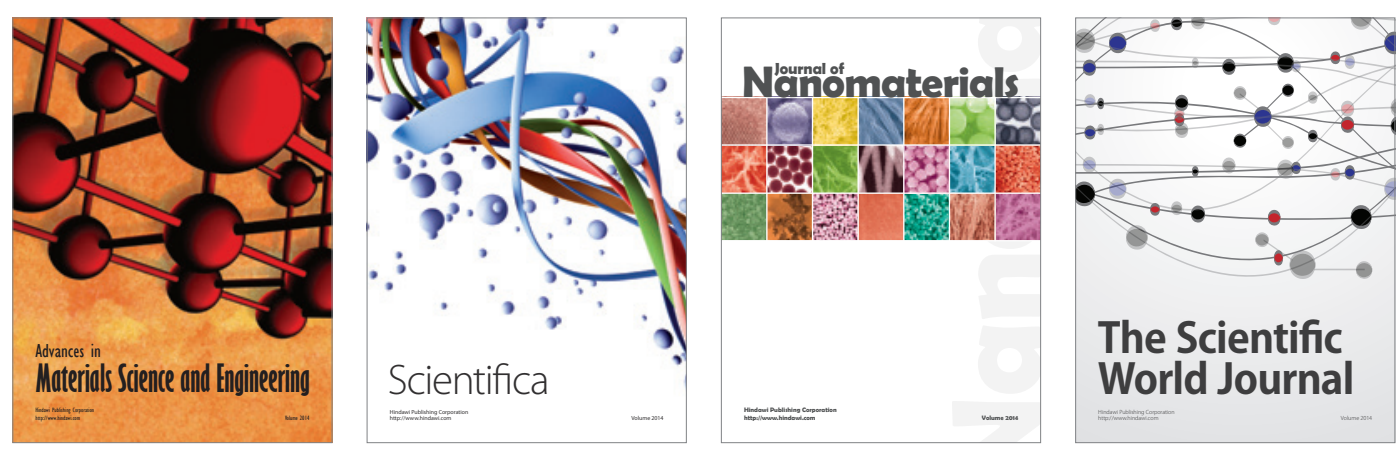

\section{The Scientific World Journal}
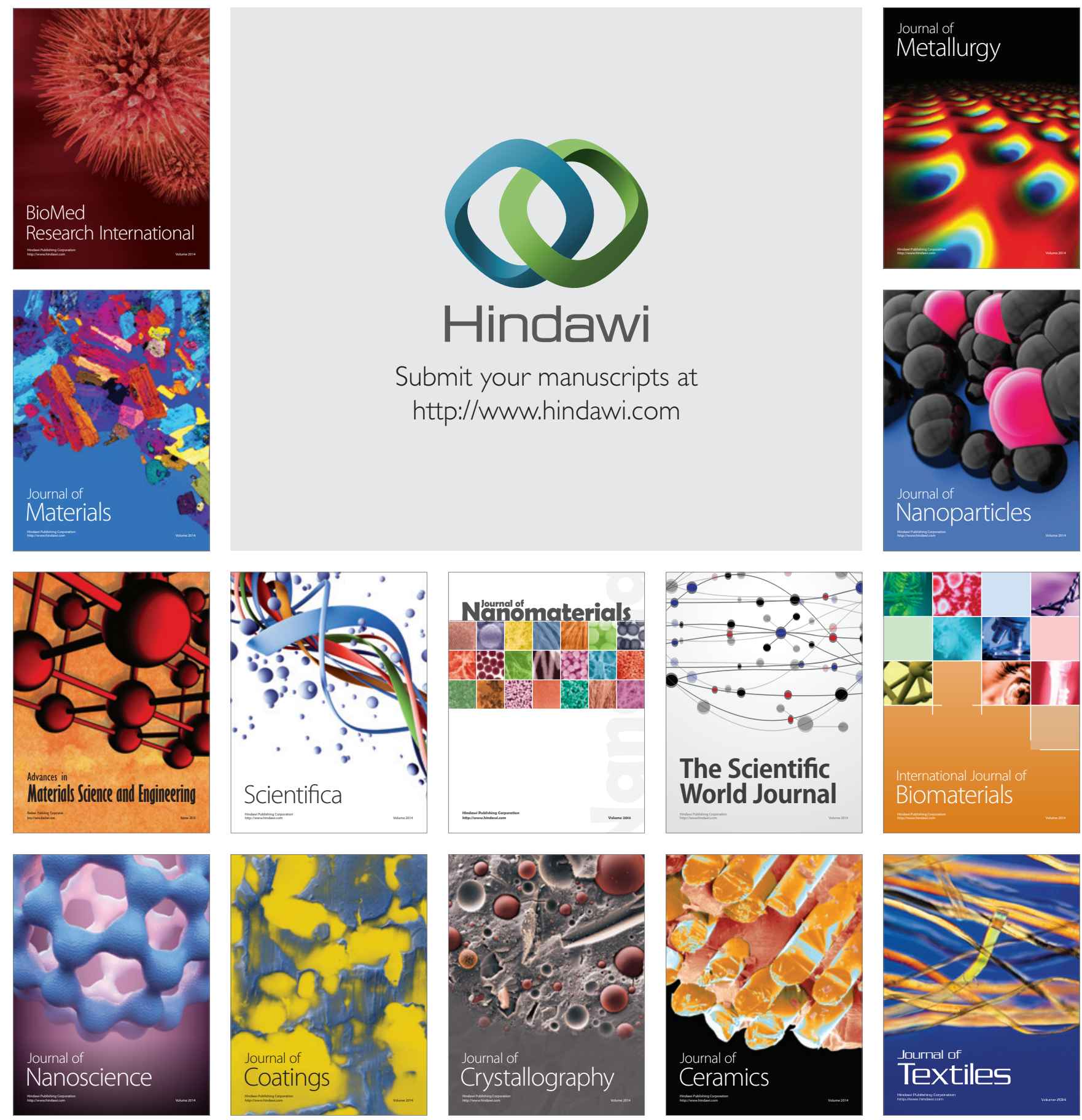